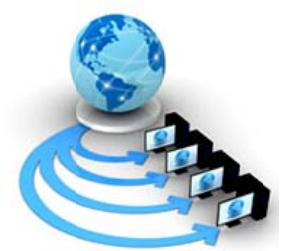

Volume 9, No. 1, January-February 2018

International Journal of Advanced Research in Computer Science

RESEARCH PAPER

\author{
Available Online at www.ijarcs.info
}

\title{
ENERGY EFFICIENT CLUSTERING PROTOCOL IN WIRELESS SENSOR NETWORK FOR PRECISION AGRICULTURE
}

\author{
Mohd. Wasim Alam \\ Department of Electronics \& Communication Engineering, \\ AFSET, Faridadbad, Haryana, India
}

\author{
Amit Choudhary \\ Department of Electronics \& Communication Engineering, \\ Jamia Millia Islamia, New Delhi, India
}

\author{
Syed Akhtar Imam \\ Department of Electronics \& Communication Engineering, \\ Jamia Millia Islamia, New Delhi, India
}

\begin{abstract}
Wireless sensor networks offer a cost effective real time data monitoring tool for precision agriculture applications. Sensor nodes can be installed in farms or green house for mentoring soil properties like moisture, pesticide levels, air temperature and humidity levels. Measured data, as feed to decision software, can be used to precisely control irrigation system, fertilization system and air conditioners for controlling climate temperature and humidity levels of green house. In this manner, proper inputs are applied to crops leading to better crop health and yield. Low power consumption and reliable data transmission are two crucial design objectives for WSN in precision agriculture. An energy efficient clustering based routing protocol is proposed in the present paper. Cluster forwarder head node is elected by sink node on the basis of cost function of node residual energy; network total energy and node distance from sink. Node nearby to sink and having maximum energy iselected as forwarder. Forwarder collects data packets of subordinate nodes and forms a single reduced bit-count datum from received packets. For this, forwarder node omits similar received data packets. Forwarder transmit datum to sink and energy efficiency is increased by reducing the size of datum. Proposed protocol shows better performance in terms of network lifetime, stability and throughput as compared to existing protocols.
\end{abstract}

Keywords:Wireless Sensor Network,Preccision Agriculture, Routing protocol, Clustering protocol, Network lifetime

\section{INTRODUCTION}

Farmers in India do not care for testing soil characteristics and generally stay ignorant of soil conditions of their agricultural land. Moreover there is no encouragement from state regarding soil testing and soil testing labs are not commonly available. [1] Farmers can be benefitted a lot from the knowledge of soil attributes like soil wetness content, soil element composition, pesticide level and atmospheric condition like air temperature and air moisture levels in their farmland or green house. Based on Such information, farmers can provide required inputs to their crop like proper irrigation, and fertilization to their crops. [2]

Such soil properties can be measured by taking soil samples and taking it to soil testing labs. But regular sampling becomes harmful for ripening up crops. [1,3] Wireless sensor networks have proven themselves very helpful for precision agriculture applications [2,4]. Multiple sensor nodes, capable of sensing various soil and air characteristics are grounded to farmland or green house. These node sense farmland condition parameters and send data to base station. Base station computer after necessary processing, upload this data to internet cloud using IOT techniques. Farmer can access this data regarding soil and atmospheric conditions on his smart phone using internet connection from anywhere in the world. for this Taylor made android application can be designed. [5,6] Based on this real time information availability, farmers becomes aware regarding soil and atmospheric conditions and can provide required inputs to their crop like proper irrigation, and fertilization to their crops (Figure 1). [3,7]

On individual basis, such technical solutions can be costly. A WAN based wireless sensor network can be designed and installed to observe a vast geographical region and can serve multiple number of villages, town or district as well. [1] A cooperative model based department can be established by government or a company for the purpose in order to help thousands of farmers at reasonable charges.

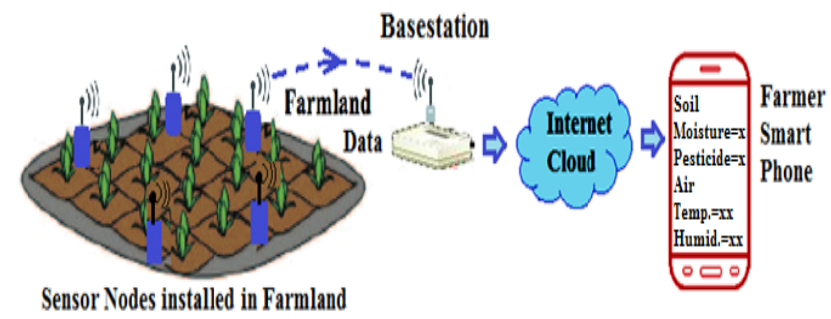

Fig. I. Use of WSNs in Precision Agriculture

Nodes in a wireless sensor network have tiny battery which gets exhausted in a short period of time due to nonstop measurement of parameters at high sampling rates. [8] Dead node reduce network lifetime and degrades its quality of service in terms of high data packet loss rates and end to end delay. High energy efficiency along with high throughput and low latency are significant design goals for wireless sensor networks for precision agricultureapplication. 
Data communication consumesmost of node power and communication power expenditure increases in square with communication distance. [9] A routing protocol continuously searches shortest multi hop data reporting paths from source to sink node. Routing protocol dynamically changes multihop routing path in between transmitting and receiving nodes as well. By dynamically changing routing paths, a routing protocol balances data communication load among network nodes. [10]

Clustering based routing protocols are suitable for WSN application. High energy forwarder node in a cluster group collects data packets from subordinate source nodes of cluster. Forwarder node first performs data aggregation (data fusion) on received packets and compresses them into a single data packet of reduced size. Cluster head then throw this aggregated data packet to sink. Clustering routing is energy efficient as they incorporate data aggregation. [11]

A wide range of research works done in the field ofWSN application based precision agriculture is available in existing literature. Below is a concise review of some of them.R. Beckwith, et.al,[4] proposed the design of wireless sensor network for large scale deployment in agriculture. Using scientific methods, authors proved that high spatial resolution monitoring of farmland environmental parameters and proper crop inputs offer increased crop quality and quantitywith good returns.Authors presented a detailed analysis of the benefits gained from the investment in WSNs for agricultural applications. Similarly Luis Ruiz-Garcia et.al [3] studied the benefits obtained from recent developments in the field of different sensor and wireless communication technologies like ZigBee based WSN, passive, semi-passive \& active RFID in context of Agriculture and Food Industry. Authors proposed the integration of WSN and RFID technologies in order to achieve efficient sensing and communication of data.Few of the existing clustering based networks protocol are surveyed with their merits and demerits as follow. A popularly known clustering routing protocol, as proposed by Wendi Rabiner Heinzelman, et.al, [11],is LEACH. LEACH elects new cluster forwarders for each transmission cycle. Cluster forwarder node election is probabilistic and is carried away on the basis of probable number of forwardersin current transmission cycle and last condition of the node as forwarder. Remaining nodes becomes child nodes of selected cluster forwarder (which ever is nearer to them).Cluster forwarder selection is random and forwarder job is not distributed among network nodes uniformly. It leads to non uniform node energy dissipation in the network. Protocol performance gets worsen in case of heterogeneous networks. SEP (Stable Election Protocol) by Georgios Smaragdakis et.al, [12] is an extension of LEACH for heterogeneous networks. Heterogeneous networks use different residual energy levels for sink and sourcenodes.SEP provides better performance in case of heterogeneous networks.

Design and Matlab based simulation of a new energy efficient WSN clustering based routingprotocol for green house farmingapplication is presented. Cluster head forwarder selection is carried out on the basis of a cost function of several parameters like node residual energy, node closeness to sink and node connectivity to neighbour nodes. Protocol performance (Network-lifetime, Network- stability and Network-throughput) is compared with existing protocols and found to be superior.

If outline of the presented paper is talked about then, section 2 discuss the target WSN system model and section 3 elaborates the proposed protocol. Simulation results are given in section 4 . Section 5 concludes the paper along with the future scope.

\section{SYSTEM MODEL}

WSN system used in the present work contains eight sensor nodes installed at different indoor locations of a $20 \mathrm{~m} \mathrm{X} 20 \mathrm{~m}$ green house (Figure 2).Green house is partitioned into 6 grids implanted with tomato crop. Each grid is provided with one soil moisture senor. One air temperature sensor and one air humidity sensor are installed at roof of green house.Table- 1 contains the details of sensor nodes.

Table I.
\begin{tabular}{|c|c|c|}
\hline Sensor & Location & $\begin{array}{c}\text { Parameter } \\
\text { Sensed }\end{array}$ \\
\hline S1 & Grid-G1 & Soil Wetness \\
\hline S2 & Grid-G2 & Soil Wetness \\
\hline S3 & Grid-G3 & Soil Wetness \\
\hline S4 & Grid-G4 & Soil Wetness \\
\hline S5 & Grid-G5 & Soil Wetness \\
\hline S6 & Grid-G6 & Soil Wetness \\
\hline S7 & Roof & $\begin{array}{c}\text { Atmospheric } \\
\text { Relative Humidity }\end{array}$ \\
\hline S8 & Roof & $\begin{array}{c}\text { Ambient } \\
\text { Temperature }\end{array}$ \\
\hline SINK & Center & -- \\
\hline
\end{tabular}

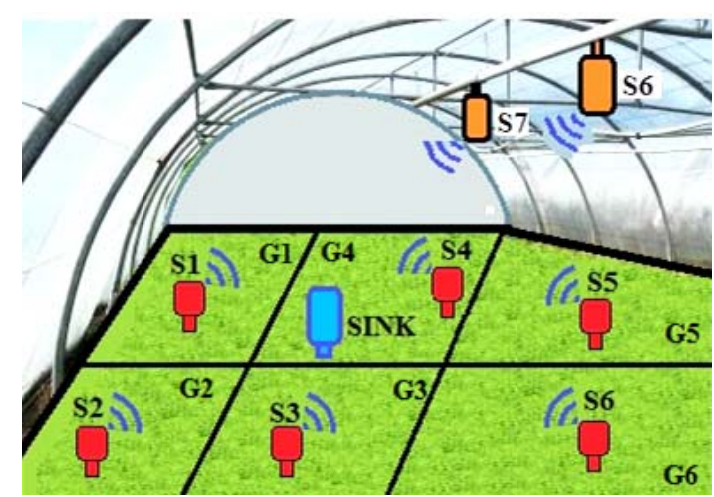

Fig. II. Sensor Node Positions Inside Green House

\section{A. WSN Architecture:}

Sensors $7 \& 8$ are air temperature and humidity sensors. They communicate data directly to Sink. Remaining node forms a cluster and report data to sink via forwarder node. (Figure 3). 


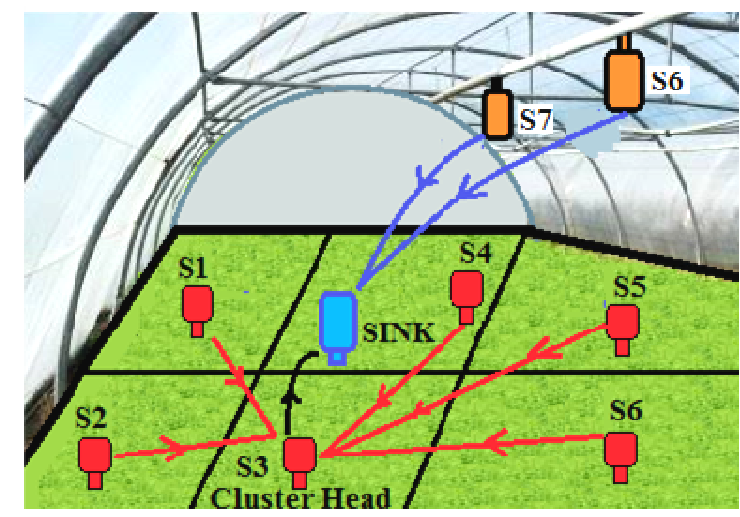

Fig. III. WSN Architechture

\section{B. Energy model:}

First order radio model as given in [11] model node data transmission energy losses. Equation-1 models node transmission energy for communication of data word of $L$-bits length to a node at a distance- $X$ away. Node energy consumed in receiving same data word is given by Equation-2

$E_{T x \text {-elect }} / E_{R x \text {-elect }}$ represent the energy per bit expanded for driving the transmitter/ receiver circuit and $E_{A m p}$ is the energy consumed in transmitter power amplifier.

\section{Assumptions:}

Following postulations are obeyed in order to make the planned work.

- Each node hasidentical battery. Node power is limited (Initial node energy $\mathrm{E}_{0}=0.5 \mathrm{~J}$ ) .

- $\quad$ Sink hasunrestricted energy reserve.

- Nodes are still. Location coordinates of each node are stored in Sink memory.

- $\quad$ Node processing energy expenditures are ignored.

- Line of Sight communication is assumed in between transmitting and receiving nodes.

- Wi-Fi wireless communication module is used as per IEEE 802.11/b/g/n standards.

\section{PROPOSED PROTOCOL}

Proposed protocol works in following phases.

\section{A. Initial Localization phase}

Before starting any sensing or communication phase, sink figure out its distance from network nodes, $D(i)$, using following equation.

$$
\text { ; } i \in(1,2 \ldots N)
$$

Where $\mathrm{N}$ is the number of network nodes. After initial localization phase, transmission rounds starts.

\section{B. Forwarder selection Phase}

Forwarder selection is sink assisted and is carried out in following phases.

(i) Cluster nodes transmit energy packets to sink one by one. Energy packets contain current energy level information $E r_{i} ; i \in(1,2 \ldots N$,) along with node ID.

(ii) If $E r_{i}<=0$ then sink increase dead count by 1 . dead counter $=$ dead counter +1

(iii) If $E r_{i}>0$, node-i is alive. Sink adds its energy level to current network residual energy counter.

$E_{\text {Current_residual_Energy }}=E_{\text {Current_residual_Energy }}+E r_{i}(5)$

(iv) In this manner, all nodes transmit their energy packets to sink and sink computes current number of dead nodes and current value of network residual energy for present transmission round

(v) Sink computes a cost function for each alive cluster node as follow.

(6)

Where $\mathrm{M}$ is the number of cluster nodes.

(vi) Cluster node having minimum cost function is selected as cluster forwarder. It will result in minimum network energy loss as it is a maximum residual energy $\left(E_{r}\right)$ node having closest proximity to sink $(D)$.

\section{Data sensing and transmission}

In this phase, following operations are carried out.

(i) Sensor nodes observe their assigned soil or air characteristics. During this period node transceivers are off.

(ii) Starting from node-S1, cluster subordinate nodes throw their sensed data words to forwarder on one by one basis. Sink put its transceiver ON during this phase. When a node is communicating, other nodes remain in sleeping condition with their transceiver off.

(iii) Data Fusion by redundant data omission:

Forwarder node receives data words and fuses them into single data word by omitting similar packets received. By doing so, similar redundant data measured by nodes is not transmitted and energy is saved.

(iv) Then forwarder transmits its packet to sink. Sink make its transceiver ON during this period.

(v) Then sensor-S7 transmitsair temperature data to sink.

(vi) Then sensor-S7 transmits air humidity data to sink. Figure-4 shows flow chart of proposed protocol.

\section{PROTOCOL SIMULATION}

Matlab based simulation of presented WSN protocol for precision agriculture is carried out. Table 2 contains simulation parameters. Simulation results (Networklifetime, Network stability and Network-throughput) are compared with existing protocols. 


\begin{tabular}{|l|l|}
\hline Parameter & Value \\
\hline $\begin{array}{l}\text { Energy to run node transmitter } \\
\left(E_{T X \text {-elect }}\right)\end{array}$ & $16.7 \mathrm{~nJ} / \mathrm{bit}$ \\
\hline $\begin{array}{l}\text { Energy to run node receiver } \\
\left(E_{R X-e l e c t}\right)\end{array}$ & $36.1 \mathrm{~nJ} / \mathrm{bit}$ \\
\hline $\begin{array}{l}\text { Energy to run node amplifier } \\
\left(E_{\text {Amp }}\right)\end{array}$ & $1.97 \mathrm{~nJ} / \mathrm{bit}$ \\
\hline
\end{tabular}

\begin{tabular}{|l|l|}
\hline Data packet size $(W)$ & 4000 \\
\hline Transceiver frequency $f$ & $2.4 \mathrm{GHz}$ \\
\hline Network Area & $20 \times 20 \mathrm{~m}^{2}$ \\
\hline Number of nodes & 8 nodes and 1 sink \\
\hline Initial node energy $E_{o}$ & $0.6 \mathrm{~J}$ \\
\hline Threshold energy $E_{T h r}$ & $0.1 \mathrm{~J}$ \\
\hline
\end{tabular}

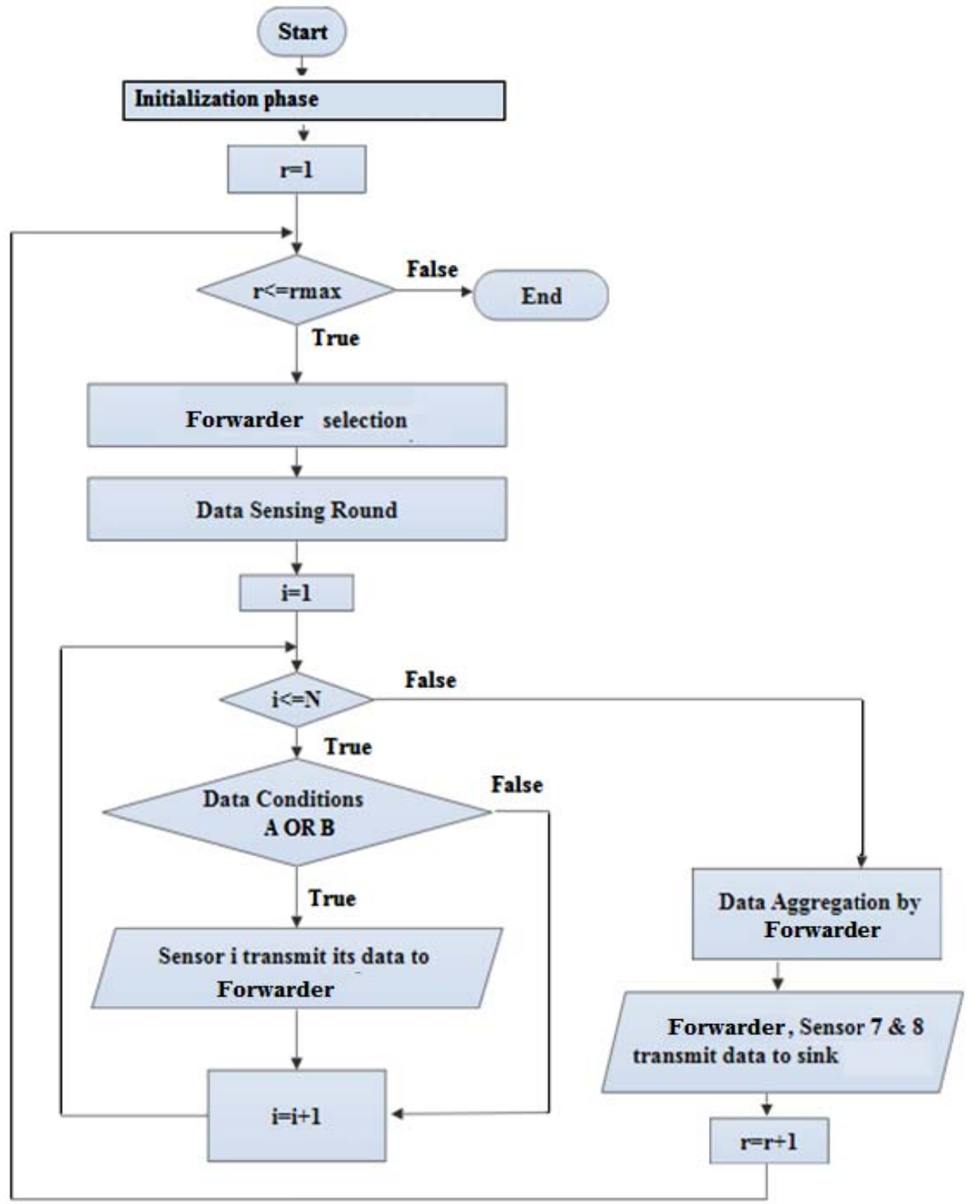

Fig. IV. Proposed protocol flow chart

\section{Performance parameters:}

\section{i) Network lifetime}

Network lifetime is obtained in form of a graph in between number of dead nodes and transmission round.Thus the round number when all nodes get died is taken as network lifetime Figure-5 shows the result for network lifetime.

\section{ii) Network stability period}

Number of round when very first node gets died is termed as networkstability period. Figure-6 shows the result for network stability period.

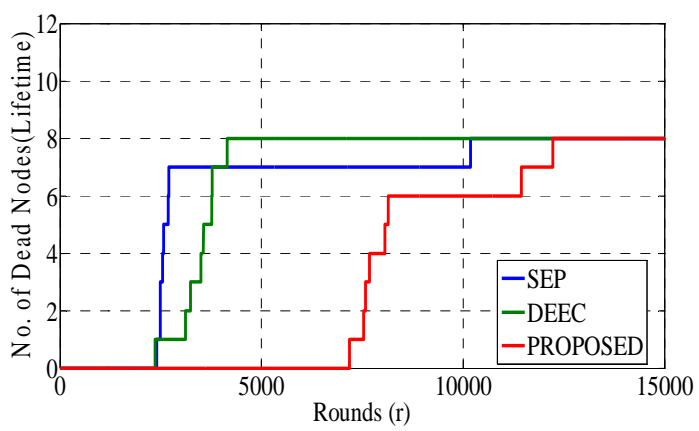

Fig. V. Network-Lifetime: number of dead node per round 


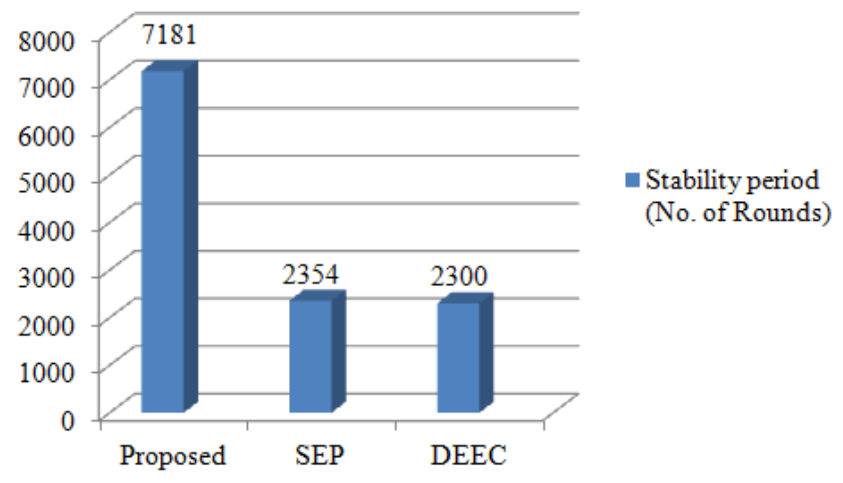

Fig. VI. Stability Period

\section{iii) Network throughput}

Network throughput is the number of packets successfully transmitted to sink. Figure-7 shows the result for network throughput.

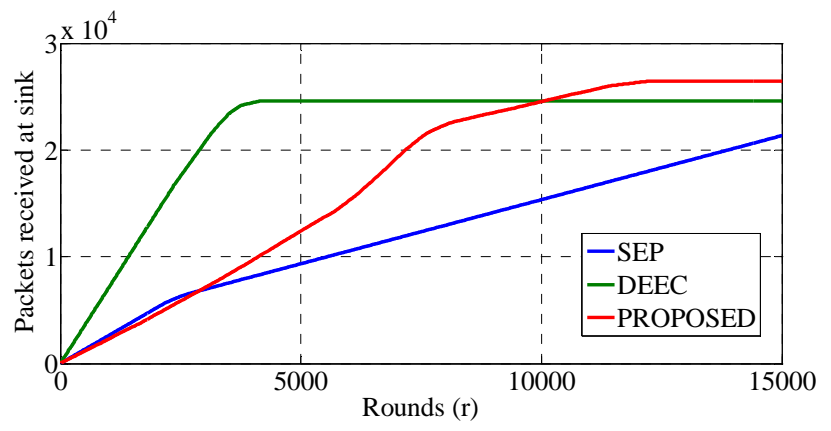

Fig. VII.Network-Throughput: data packet sucessfully delivered to sink

\section{iv) Network latency}

Equation 7 can be used to count propagation delay in a transmission for distance d(s,r) in between transmitting and receiving nodes.

$$
\text { propagation_delay }=\frac{d(s, r)}{c}
$$

Where $d(s, r)$ is represents the transmission range and $c$ is the light speed for signal. Results for total end to end latency in signal transmission are shown in Figure-8.

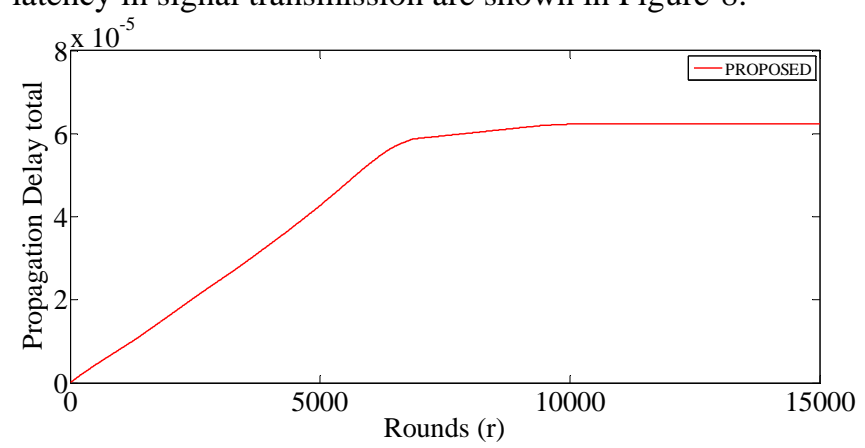

Fig. VIII. Network-Throughput: data packet successfully delivered to sink

Proposed protocol shows better performance in terms of network lifetime, stability and throughput as compared to existing protocol. Data fusion process performed by forwarder node removes similar data packets of child nodes from transmission. In this manner node transmission energy is saved resulting in improved network lifetime. Elongated network lifetime and reduced data traffic load on network channels results in higher packet count reaching sink. this provide the network with higher throughput. Two hop clustering reults in lower ened to end latency as well.Table 3 compares the proposed protocol with existing SAP protocol.

\begin{tabular}{|c|c|c|c|}
\hline Table III. & : PROTOCOL COMPARISON \\
$\begin{array}{c}\text { Performanc } \\
\text { e parameter }\end{array}$ & $\begin{array}{c}\text { Netwo } \\
\text { k } \\
\text { Lifeti } \\
\text { me }\end{array}$ & $\begin{array}{c}\text { Stabili } \\
\text { ty } \\
\text { period }\end{array}$ & $\begin{array}{c}\text { Throughp } \\
\text { ut } \\
\text { (Packets } \\
\text { received } \\
\text { at Sink) }\end{array}$ \\
\hline (Proposed) & $\begin{array}{c}12230 \\
\text { Round } \\
\text { s }\end{array}$ & $\begin{array}{c}7181 \\
\text { Round } \\
\text { s }\end{array}$ & $2.64 \times 10^{4}$ \\
\hline SAP & $\begin{array}{c}10190 \\
\text { Round } \\
\text { s }\end{array}$ & $\begin{array}{c}2354 \\
\text { Round } \\
\text { s }\end{array}$ & $2.12 \times 10^{4}$ \\
\hline DEEC & $\begin{array}{c}4145 \\
\text { Round } \\
\text { s }\end{array}$ & $\begin{array}{c}2300 \\
\text { Round } \\
\text { s }\end{array}$ & $2.45 \times 10^{4}$ \\
\hline
\end{tabular}

\section{CONCLUSION AND FUTURE WORK}

An energy efficient clustering based routing protocol was proposed for WSN precision agriculture application. Proposed protocol was targeted for wireless sensor network application for green house based agricultural application. Eight sensor nodes are deployed in a $20 \mathrm{~m} \mathrm{X} 20 \mathrm{~m}$ green house. Green house is partitioned into 6 grids implanted with tomato crop. Each grid is provided with one soil moisture senor. One air temperature sensor and one air humidity sensor are installed at roof of green house. Six moisture sensor nodes form a cluster. Air temperature humidity sensor directly transmit their data to sink.Node residual energy, network total energy and node distance from sink are used to calculate cost function for a node to be selected as forwarder. Node closest to sink and having highest energy is selected as forwarder. Forwarder receives packets of cluster subordinate nodes. Forwarder forms a single aggregated datum from received packets by omitting similar received data packets. Forwarder transmit datum to sink. Proposed protocol shows better performance in terms of network lifetime, stability and throughput as compared to existing protocol. In future proposed protocol can be implemented with more number of sensor nodes in a real platform.

\section{REFERENCES}

[1] S. A. Imam, A. Choudhary and V. K. Sachan, "Design issues for wireless sensor networks and smart humidity sensors for precision agriculture: A review," 2015 International Conference on Soft Computing Techniques and Implementations (ICSCTI), Faridabad, 2015, pp. 181-187. doi: 10.1109/ICSCTI.2015.7489591

[2] C. T. Kone, A. Hafid and M. Boushaba, "Performance Management of IEEE 802.15.4 Wireless Sensor Network for Precision Agriculture," in IEEE Sensors Journal, vol. 15, no. 10, pp. 5734-5747, Oct. 2015.

[3] Luis Ruiz-Garcia et.al, "A Review of Wireless Sensor Technologies and Applications in Agriculture and Food 
Industry: State of the Art and Current Trends ", Sensors Journal, Vol. 9, pp-4728-4750, 2009.

[4] R. Beckwith, et.al, "Unwired wine: sensor networks in vineyards”, Proc. IEEE Sensors-2004, vol.2, PP- 561- 564 Oct. 2004.

[5] D. Pavithra, et.al, "IoT based monitoring and control system for home automation", in proc. IEEE Global Conference on Communication Technologies (GCCT), 2015, PP: 169 - 173, 23-24 April 2015

[6] S. A. Imam, A. Choudhary, A. M. Zaidi, M. K. Singh and V. K. Sachan, "Cooperative effort based wireless sensor network clustering algorithm for smart home application," 2017 2nd IEEE International Conference on Integrated Circuits and Microsystems (ICICM), Nanjing, 2017, pp. 304-308.

[7] doi: 10.1109/ICAM.2017.8242190

[8] Silviu C. Folea, et.al., "A Low-Power Wireless Sensor for Online Ambient Monitoring”, IEEE Sensors Journal, Vol. 15, No. 2, PP- 742-749, February 2015

[9] I.F. Akyildiz, W. Su, Y. Sankarasubramaniam, E. Cayirci, "Wireless sensor networks: a survey," in Computer Networks, Volume 38, Issue 4, 2002, Pages 393-422, ISSN 1389-1286.
[10] Vibhav Kumar Sachan, Syed Akhtar Imam, M. T. Beg, "Energy-efficient Communication Methods in Wireless Sensor Networks: A Critical Review”, International Journal of Computer Applications (0975 - 8887), vol. 39, no. 17, February 2012.

[11] N. A. Pantazis, S. A. Nikolidakis and D. D. Vergados, "Energy-Efficient Routing Protocols in Wireless Sensor Networks: A Survey," in IEEE Communications Surveys \& Tutorials, vol. 15, no. 2, pp. 551-591, Second Quarter 2013. doi: 10.1109/SURV.2012.062612.00084

[12] Wendi Rabiner Heinzelman, Anantha Chandrakasan, and Hari Balakrishnan, "Energy-Efficient Communication Protocol for Wireless Microsensor Networks," in Proc. of the 33rd Hawaii International Conference on System Sciences- (HICSS '00), Vol. 8, 10 pages, IEEE Computer Society, Washington, DC, USA.

[13] Georgios Smaragdakis and Ibrahim Matta and Azer Bestavros, "SEP: A Stable Election Protocol for clustered heterogeneous wireless sensor networks," in Proc. Second International Workshop on Sensor and Actor Network Protocols and Applications (SANPA 2004), August 2004 , Boston, MA 